\title{
Thermal Characterization of the Overload Carbon Resistors
}

\author{
Ivana Kostić, ${ }^{1}$ Ljubiša Tomić, ${ }^{1}$ Aleksandar Kovačević, ${ }^{1}$ and Saša Nikolić ${ }^{2}$ \\ ${ }^{1}$ Technical Test Center, Vojvode Stepe 445, 11000 Belgrade, Serbia \\ ${ }^{2}$ Faculty of Electrical Engineering, University of Niš, Aleksandra Medvedeva 14, 18000 Niš, Serbia \\ Correspondence should be addressed to Ivana Kostić; kostic.ici@gmail.com
}

Received 10 May 2013; Accepted 17 June 2013

Academic Editor: Momčilo Pejović

Copyright (C) 2013 Ivana Kostić et al. This is an open access article distributed under the Creative Commons Attribution License, which permits unrestricted use, distribution, and reproduction in any medium, provided the original work is properly cited.

In many applications, the electronic component is not continuously but only intermittently overloaded (e.g., inrush current, short circuit, or discharging interference). With this paper, we provide insight into carbon resistors that have to hold out a rarely occurring transient overload. Using simple electrical circuit, the resistor is overheating with higher current than declared, and dissipation is observed by a thermal camera.

\section{Introduction}

The electronic designers must be sure that the correct device is chosen on the basis of both electrical and thermal performances. Many companies have established their own standards and testing techniques based on their experience, but often this information is not enough. It is necessary to know the operating life of electronic components affected by temperature and voltage stress. Measurement and temperature control are becoming increasingly important especially since device and electronic board sizes are shrinking.

Temperature measurement is not easy but is necessary since it is the only measurable parameter for the quality of the thermal design [1]. Every electronic component requires dedicated approaches according to its specific functionality.

One of the most frequently used electronic components is resistor. Resistor can be connected in various networks where it acts as voltage dropper, voltage divider, or current limiter. Resistors reduce the voltage or current signal passing through them. A higher voltage makes the electrons move faster through resistor and it warms up the resistor. As a result, energy is turned into heat. Typical values for this parameter are $1 / 16 \mathrm{~W}, 1 / 10 \mathrm{~W}, 1 / 8 \mathrm{~W}, 1 / 4 \mathrm{~W}, 1 / 2 \mathrm{~W}, 1 \mathrm{~W}, 2 \mathrm{~W}$, $2.5 \mathrm{~W}, 3 \mathrm{~W}$, or higher to $100 \mathrm{~W}$ or even $300 \mathrm{~W}$. For the thermal problem, given that energy is not the only restriction parameter, the temperature will increase faster reducing the size of the resistor because the power dissipation capability is directly proportional to size. Also, a system that will reduce the temperature rise of electronic parts and equipment is necessary [2].

\section{Experimental Setup}

Measurements were performed by heating the resistor by electric current. The propagation of the heat is a physical process and depends on the thermal properties of materials, size of the area, and length of the wire. Because of the small area of the resistor, contact methods can easily change the value of surface temperature. So this method is worthless for this kind of measurements [3]. Most of the light is radiated at infrared (IR) wavelengths, but at sufficiently high temperatures there is a considerable amount of light also at visible wavelengths. This amount of radiated heat energy has $\sim \mathrm{T}^{4}$ dependency assuming that it is by natural convection $[4,5]$.

In this experiment, it is not important to know the exact temperature of the resistor, but rather how fast temperature rises and its influence on resistor. The process is observed by an infrared camera. In this case, we used FLIR SC 620 camera, manufactured by FLIR Systems. With an operational range of $7.5 \mu \mathrm{m}-13 \mu \mathrm{m}$ band at temperatures between $0^{\circ} \mathrm{C}$ and $+500^{\circ} \mathrm{C}$, it is equipped with a $45^{\circ}$ lens and enables capturing structures by FPA (focal plane array) microbolometer set to a rate of 120 frames per second. The major technical specifications of the camera used in this study are listed in Table 1. The readout 


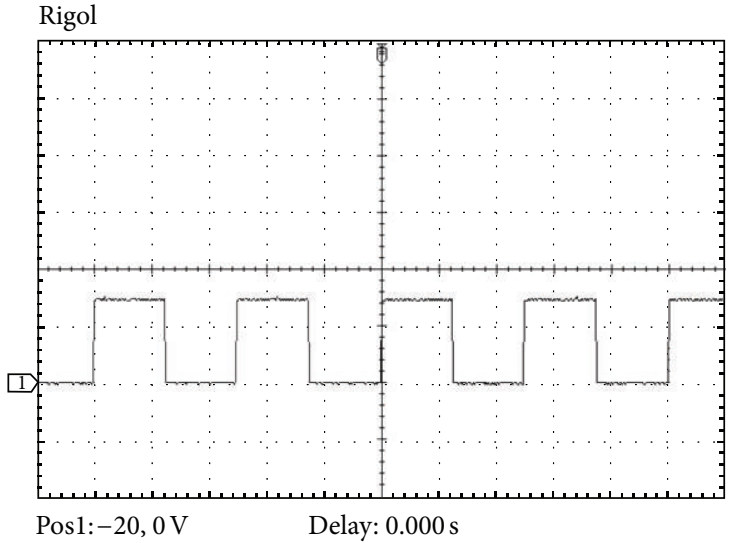

(a) Input signal $15 \mathrm{~V}$

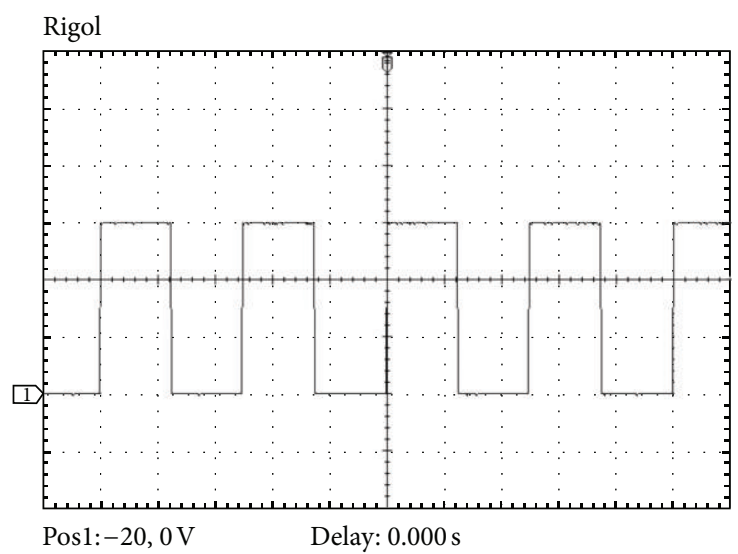

(b) Input signal $30 \mathrm{~V}$

FIGURE 1: Characteristics of input signals.

TABLE 1: Technical specifications of FLIR SC 620 infrared camera.

\begin{tabular}{lc}
\hline $\begin{array}{l}\text { Field of view } \\
\text { (FOV) }\end{array}$ & $45^{\circ} \times 34^{\circ}$ \\
\hline $\begin{array}{l}\text { Minimum focus } \\
\text { distance }\end{array}$ & $0.2 \mathrm{~m}$ \\
Spectral range & $7.5 \mu \mathrm{m}-13 \mu \mathrm{m}$ \\
Accuracy & $2^{\circ} \mathrm{C}$ or $2 \%$ of reading \\
Spatial resolution & $0.65 \mathrm{mrad}$ \\
IR resolution & $640 \times 480$ pixels \\
Image frequency & $30 / 60 / 120 \mathrm{~Hz}$ \\
Temperature range & $-40^{\circ} \mathrm{C}$ to $+1500^{\circ} \mathrm{C}$ \\
Thermal sensitivity & $40 \mathrm{mK}$ at $30^{\circ} \mathrm{C}$ \\
Focus & Automatic or manual \\
Laser pointer & Semiconductor AlGaInP diode laser, Class 2 \\
\hline
\end{tabular}

temperature is proportional to the IR flux coming from the scene. The main components of the signal are the thermal radiation emitted by the object (assumed to be an opaque grey body), the thermal radiation emitted by the heater, and the background radiation reflected from the object surface.

Test circuit board is very simple because of thermal spreading. The heat generated from a localized hot spot will eventually reach thermal equilibrium with its environment to minimize temperature gradients. The temperature distribution is completely different on an isolated resistor than in circuit with couple resistors. It consists of MOSFET BD135 that controls input signal as it is shown in Figure 1 and $75 \mathrm{Ohm}$ carbon resistor of $1 / 4 \mathrm{~W}$ which simulates electronic circuit with pulse excitation. In this case, MOSFET has a role of voltage regulator [6]. Resistor has a ceramic substrate which normally holds the resistor together during and after firing, so the resistor can be fired at least twice as it is tried in this experiment. It is calculated from the input signals that the maximum reached power can be $3 \mathrm{~W}$ and $12 \mathrm{~W}$ which is more than declared. Thermal characteristics of MOSFET BD135, which is used in this experiment, are given in Table 2 [7].
TABLE 2: Thermal characteristics of MOSFET BD 135.

\begin{tabular}{lccc}
\hline Characteristics & Symbol & Max & Unit \\
\hline Thermal resistance, junction to case & $\theta_{\text {JC }}$ & 10 & ${ }^{\circ} \mathrm{C} / \mathrm{W}$ \\
Thermal resistance, junction to ambient & $\theta_{\mathrm{JA}}$ & 100 & ${ }^{\circ} \mathrm{C} / \mathrm{W}$ \\
\hline
\end{tabular}

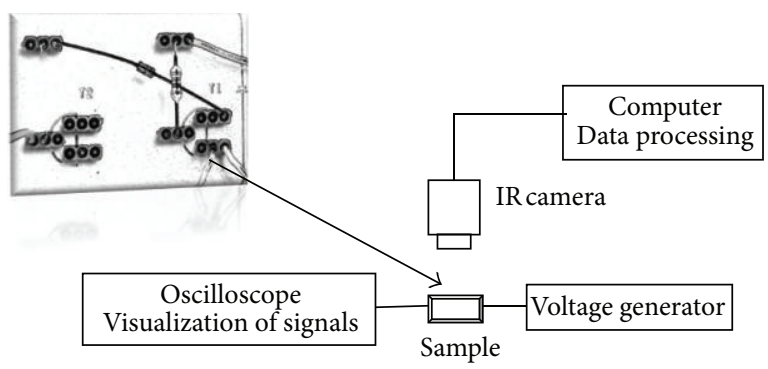

FIGURE 2: A schematic illustration of the experimental setup.

MOSFET is connected to a source supplying $15 \mathrm{~V}$ or $30 \mathrm{~V}$. Voltage through resistor (shown in Figure 1) is monitored by Rigol oscilloscope.

Using a thermal camera and an oscilloscope to observe the voltage and current through the resistor, we can gain an understanding of how a hot spot develops on the surface of the resistor. Data recording began by turning on the thermal camera and starting its Researcher software on computer (Figure 2).

The main interest of this experiment is temperature change, so we set up emission of the resistor to $\varepsilon=0.96$, distance to $0.1 \mathrm{~m}$, and temperature reflectance to $8^{\circ} \mathrm{C}$.

Observed heat is higher than preferred value ranges and carbon resistor is discoloured soon (Figure 3). Five minutes after heating, we checked resistance and it has not changed; it was within the margin of the error (error is $5 \%$ as the manufacturer declared).

Also, after we had stopped the heating, we checked the resistance when the thermal camera showed a temperature of $100^{\circ} \mathrm{C}$ and it was within the limits of error. Heat dissipation 


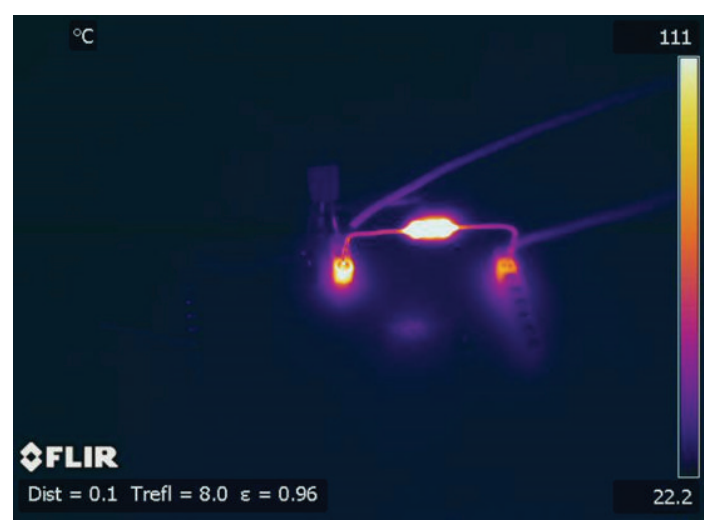

(a) Recorded sequence thermogram (INS0240.SEQ, 53rd frame), during pulse excitation

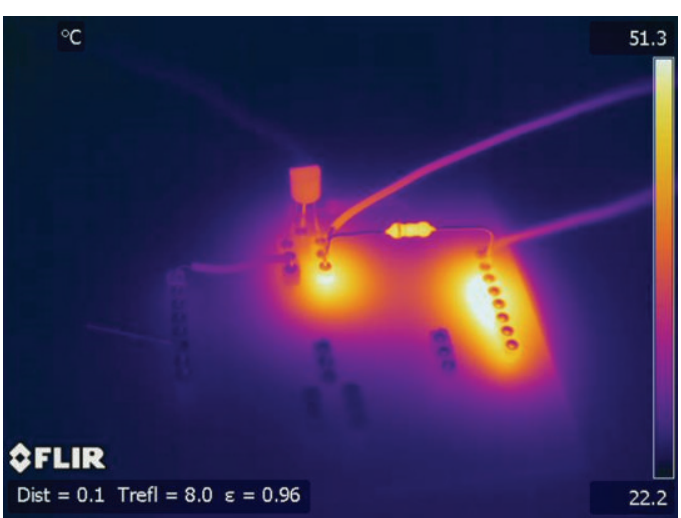

(b) Recorded sequence (INS0240.SEQ, 1500th frame), thermogram after pulse excitation

FIGURE 3: Thermogram of the resistor in electronic circuit with pulse excitation.

is high and the resistor does not lose its resistance, but it has an influence on the board and on the other components at the board. After pulse excitation, when surface temperature of resistor was near $50^{\circ} \mathrm{C}$, we noticed that resistor was cooling faster than some points of the board [8-10].

The process of heating is very fast because the resistors were heating by current 10 times higher than it is declared. Temperature was changing very fast, so it was necessary to use fast thermal camera for measurements [8]. Because of the small dimension of a resistor, it is impossible to measure temperature transition by contact methods. Each test runs for 1-2 minutes after turning on the test circuit. Resistor temperature profiles were monitored from 3 different aspects as it is shown in Figure 4.

\section{Results and Discussion}

In Figure 5(a), steady-state condition is reached in a short time after $10-15$ seconds. It is shown that the maximum temperature is reached in the centre of the resistor as it was expected (red curve) [9-11]. Red and green curves represent temperature profiles taken from LI02 and LI04 lines as it is shown in Figure 4(a). Internal parameters of the resistor lead to changes in maximum generated power $[12,13]$. It is important to study the variation of power from a technological point of view. In recent papers, the efficiency and properties in terms of various conditions have been observed $[14,15]$.

Line LI01 in Figure 4(b) represents temperature profile of the resistor taken from one frame as proof of different heat distribution as it is shown in Figure 5(b).

During testing, we wanted to know the temperature profile for the resistor in DC current circuit (Figure 6). Temperature profile is observed at lines in Figure 4(a) (LI02 and LI04) during excitation.

\section{Conclusion}

The limiting temperatures are those which the constituents can withstand before they oxidize, melt, or change value. The

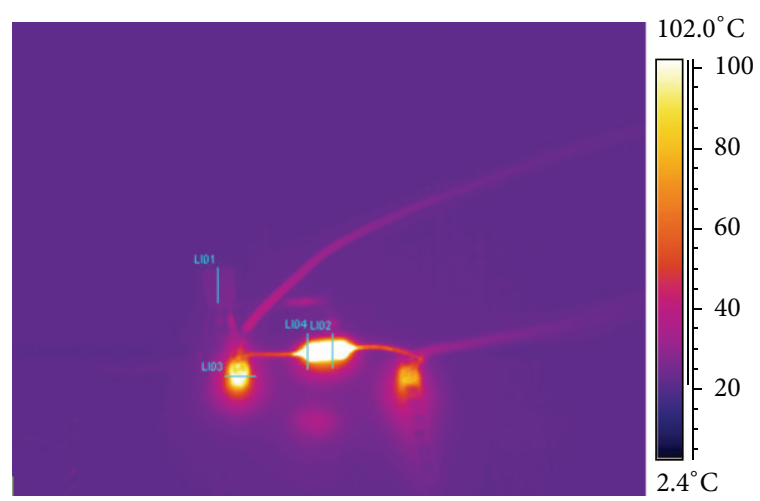

(a) Temperature in function of time for resistor in DC electronic circuit: temperature profile from LI02 and LI04 lines (INS0234.SEQ, 2004th frame)

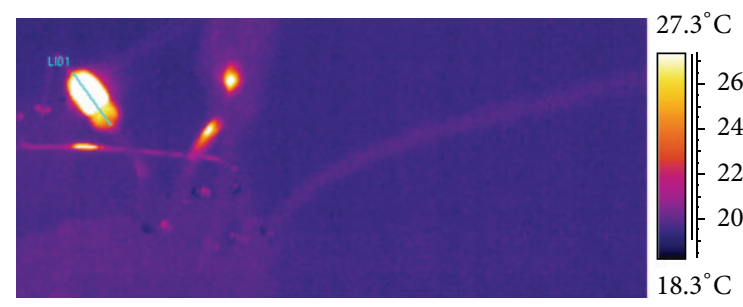

(b) Temperature in function of time for resistor in electronic circuit with pulse excitation: temperature profile from LI01 line (NEW 0010.SEQ, 640th frame)

FIgURE 4: Thermograms for resistor in DC electronic circuit and in electronic circuit with pulse excitation.

idea that there is a nonuniform distribution of temperature is demonstrated. The resistors used in this test showed excellent flame resistance. It is shown that thermography can be used during addition testing. Thermography can be used as noncontact method because it gives temperature distribution in more than a couple of points and because, in the short time, a set of measurements can be done. Because of the small area of the resistor, contact methods can easily change value of 


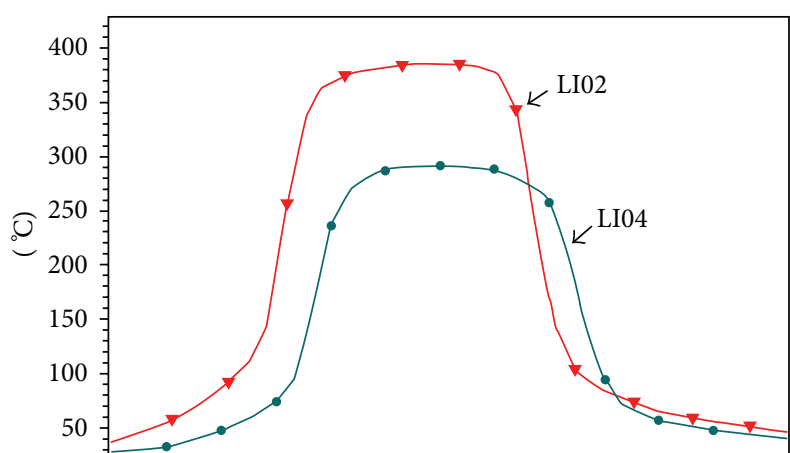

(a) Resistor temperature profile for LI02 and LI04 lines from the beginning to the end of excitation in electronic circuit with pulse excitation (INS0240.SEQ, 53rd frame)

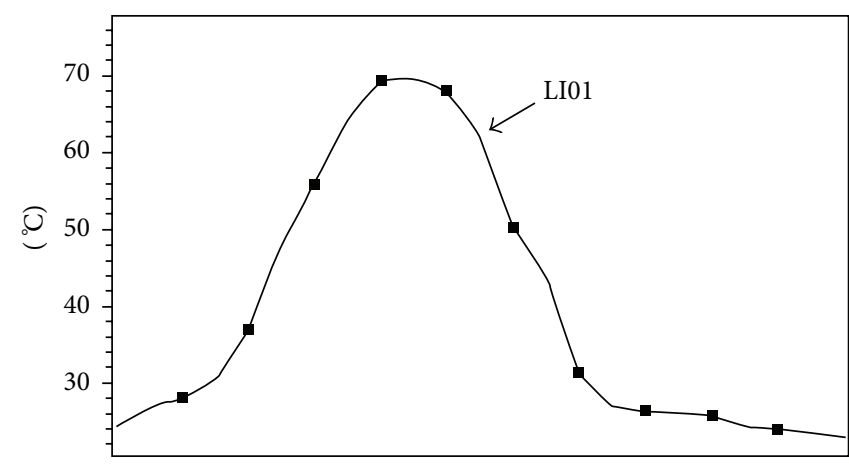

(b) Resistor temperature profile for LI01 line during excitation (NEW 0010.SEQ, 640th frame)

FIGURE 5: Resistor temperature profile from different aspects.

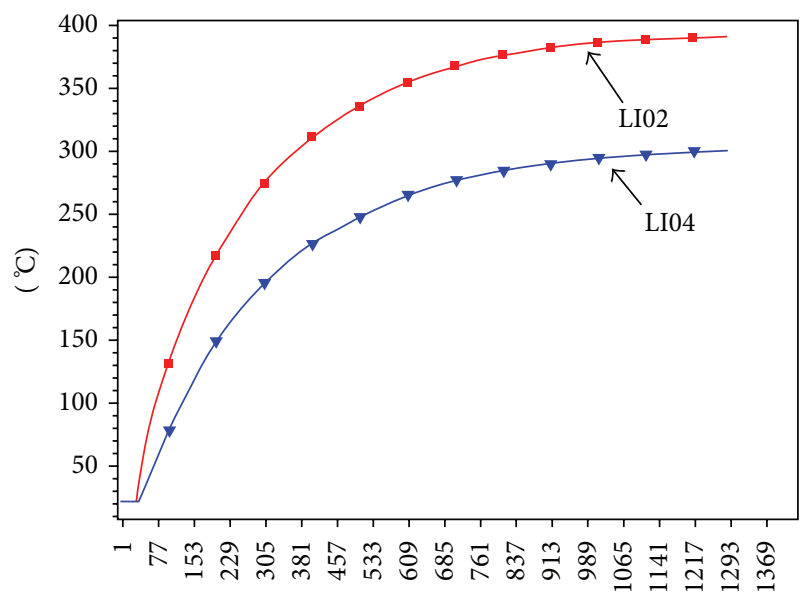

FIGURE 6: Temperature in function of time for resistor in DC current circuit (INS0234.SEQ, from 1st to 1000th frame).

surface temperature. So this method is worthless for this kind of measurements.

Also, it has been noticed that the resistor was cooling faster than some points of the board. Heat conduction of the resistor has an influence on the board and on the other components at the board which can be damaged, which can be the subject of the next research. The system must be considered by many aspects and that is why it is necessary to have cooling system or to pay more attention to construction of board.

\section{Acknowledgment}

The Ministry of Education, Science and Technological Development of Serbia supported this work under Contract III 43009 .

\section{References}

[1] Cornell Aeronautical Laboratory, Guide Manual of Cooling Methods For Electronic Equipment, vol. 25, Bureau of ships Navy Department, Washington, DC, USA, 1957.
[2] F. Windrich, "Carbon contacts and resistors in printed circuit boards-a practical overview," in Proceedings of the 1st Electronics Systemintegration Technology Conference (ESTC '06), pp. 788-793, Dresden, Germany, September 2006.

[3] C. J. Hallier, Handbook of Nondestructive Evaluation, The McGraw-Hill Companies, New York, NY, USA, 2003.

[4] A. E. Aliev, M. H. Lima, E. M. Silverman, and R. H. Baughman, "Thermal conductivity of multi-walled carbon nanotube sheets: radiation losses and quenching of phonon modes," Nanotechnology, vol. 21, no. 3, Article ID 035709, 2010.

[5] L. Sainiemi, K. Grigoras, I. Kassamakov et al., "Fabrication of thermal microbridge actuators and characterization of their electrical and mechanical responses," Sensors and Actuators A, vol. 149, no. 2, pp. 305-314, 2009.

[6] V. D. Vukić, "Minimum dropout voltage on a serial PNP transistor of a moderately loaded voltage regulator in a gamma radiation field," Nuclear Technology \& Radiation Protection, vol. 27, no. 4, pp. 333-340, 2012.

[7] "Plastic medium power silicon NPN transistor," Semiconductor Component Industries, 2005, http://www.onsemi.com/.

[8] X. P. Maldague, Theory and Practice of Infrared Technology for Nondestructive Testing, John Wiley \& Sons, New York, NY, USA, 2001.

[9] L. T. J. Elazar and B. Milanović, "Maximal temperature difference determination in pulse infrared thermography by fitting experimental results with numerical simulation curve," in Book of the Abstract III International School and Conference on Photonics, Photonica, Belgrade, Serbia, 2011.

[10] Lj. Tomić and M. Milinović, "Experimental research of limits for thermal modulation transfer function," Thermal Science, vol. 13, no. 4, pp. 119-128, 2009.

[11] "Thermalmanagement in surface-mounted resistor applications," Document Number 28844, 2011, http://www.vishay .com/.

[12] R. L. Radosavljević and A. I. Vasić, "Effects of radiation on solar cells as photovoltaic generators," Nuclear Technology \& Radiation Protection, vol. 27, no. 1, pp. 28-32, 2012.

[13] M. R. Zdravković, A. I. Vasić, R. L. Radosavljević, M. L. Vujisić, and P. V. Osmokrović, "Influence of radiation on the properties of solar cells," Nuclear Technology \& Radiation Protection, vol. 47, no. 2, pp. 152-154, 2011.

[14] T. T. Chow, G. N. Tiwari, and C. Menezo, "Hybrid solar: a review on photovoltaic and thermal power integration," International 
Journal of Photoenergy, vol. 2012, Article ID 307287, 17 pages, 2012.

[15] M. Herman, M. Jankovec, and M. Topič, "Optimal I-V curve scan time of solar cells and modules in light of irradiancelevel," International Journal of Photoenergy, vol. 2012, Article ID 151452, 11 pages, 2012. 

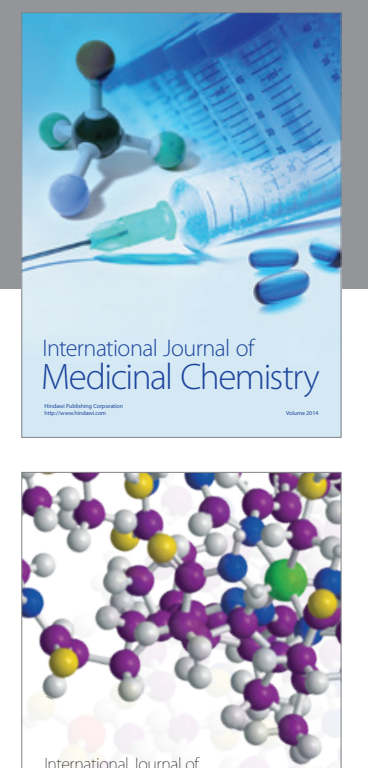

\section{Carbohydrate} Chemistry

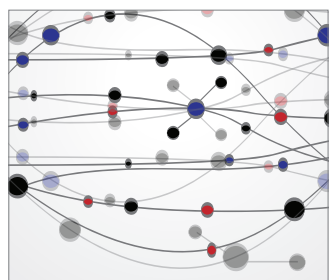

The Scientific World Journal
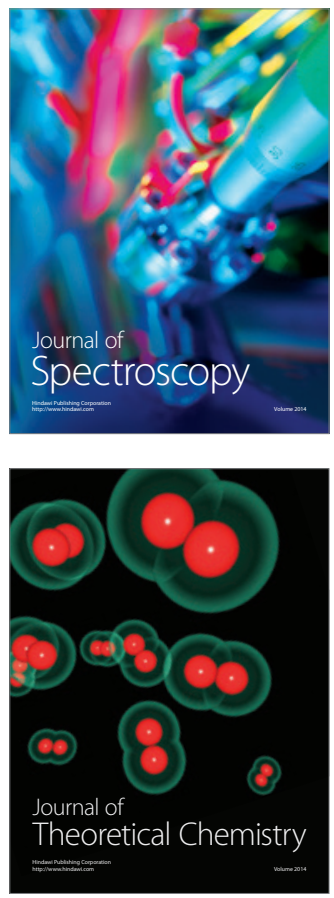
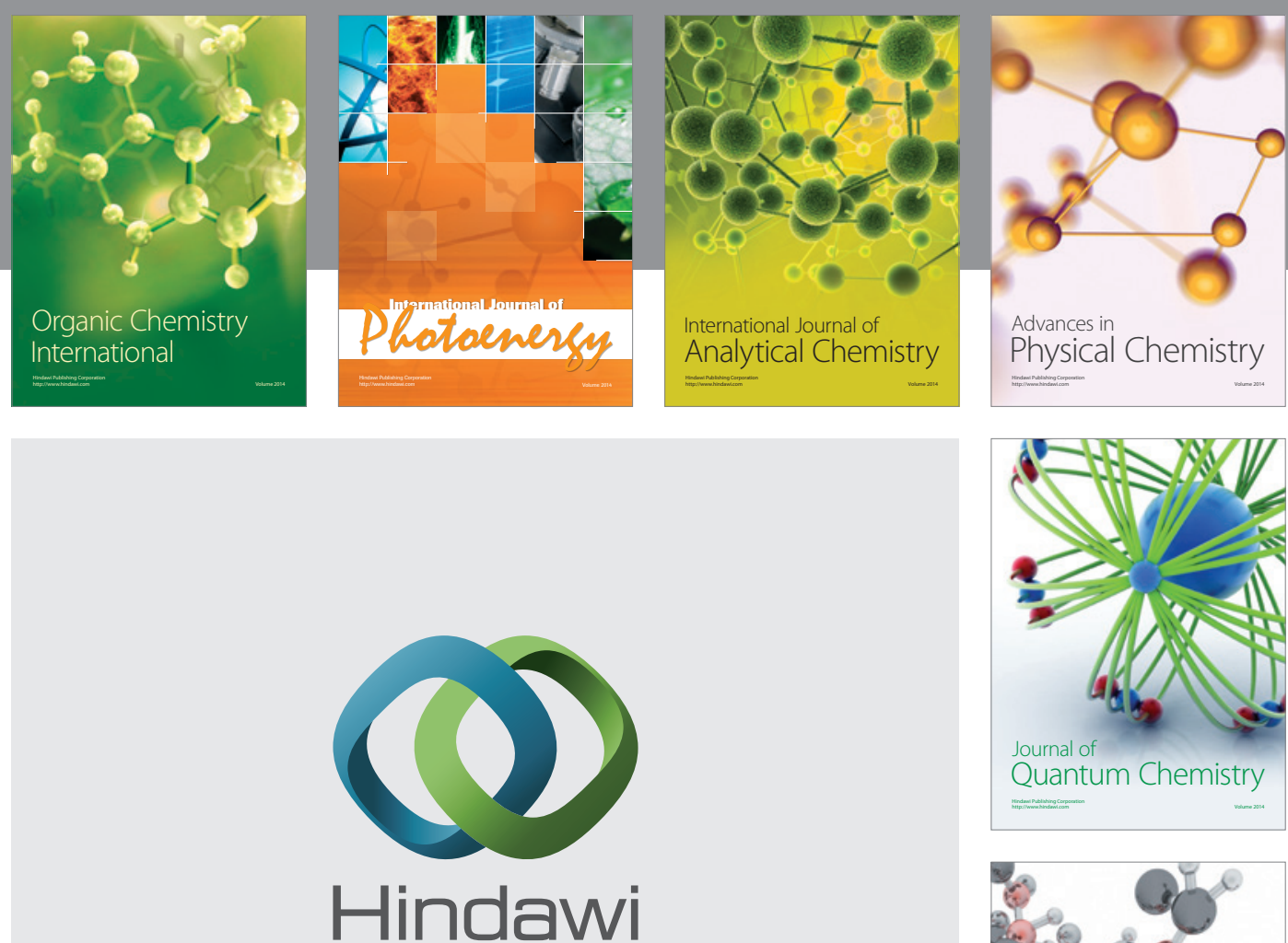

Submit your manuscripts at

http://www.hindawi.com

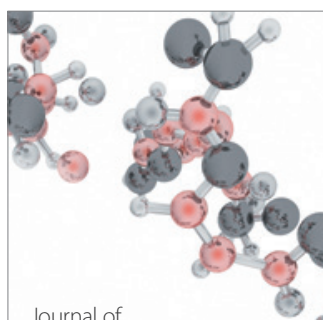

Analytical Methods

in Chemistry

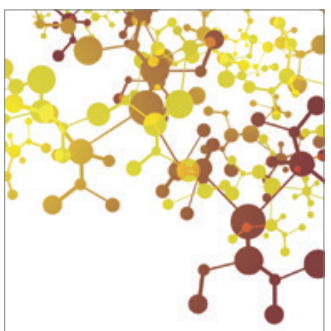

Journal of

Applied Chemistry

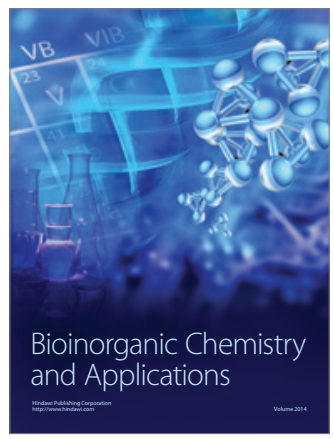

Inorganic Chemistry
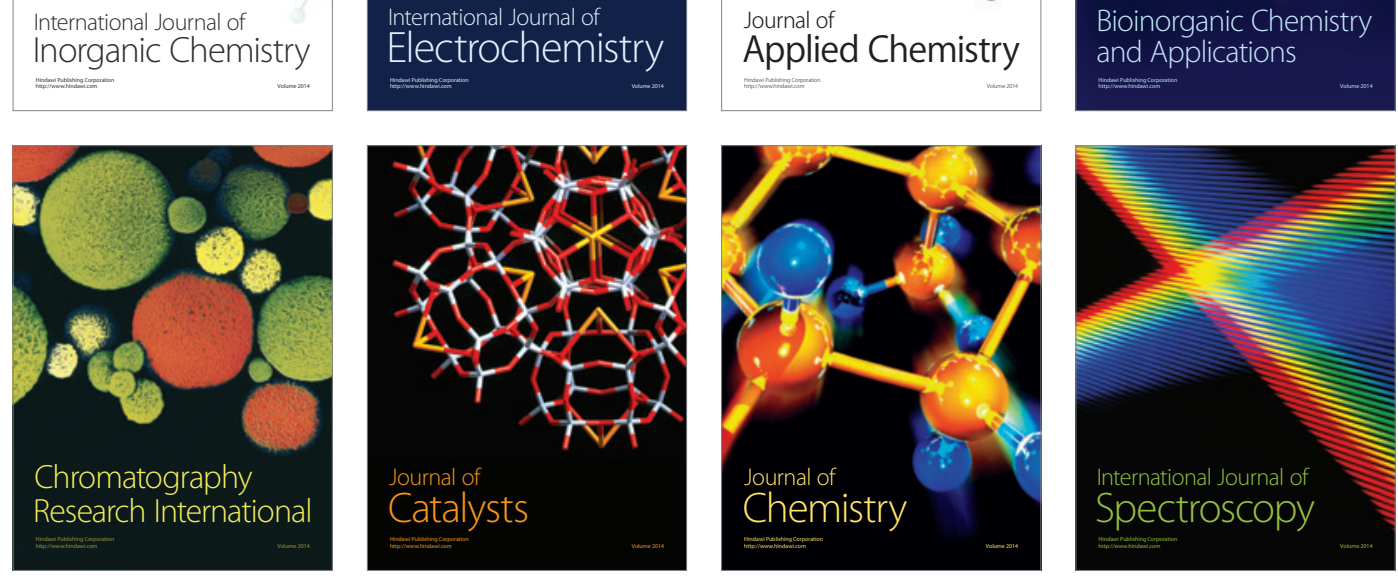